\title{
Costs of exploratory behavior: the energy trade-off hypothesis and the allocation model tested under caloric restriction
}

\author{
Isaac Peña-Villalobos ${ }^{1,2}$, Ignacio Casanova-Maldonado ${ }^{2}$, Pablo Lois ${ }^{2,3}$, Verónica Palma ${ }^{2 *} \&$ \\ Pablo Sabat ${ }^{1,4^{*}}$
}

In order to maintain the energy balance, animals often exhibit several physiological adjustments when subjected to a decrease in resource availability. Specifically, some rodents show increases in behavioral activity in response to food restriction; a response regarded as a paradox because it would imply an investment in locomotor activity, despite the lack of trophic resources. Here, we aim to explore the possible existence of trade-offs between metabolic variables and behavioral responses when rodents are faced to stochastic deprivation of food and caloric restriction. Adult BALB/c mice were acclimatized for four weeks to four food treatments: two caloric regimens (ad libitum and 60\% restriction) and two periodicities (continuous and stochastic). In these mice, we analyzed: exploratory behavior and homecage behavior, basal metabolic rate, citrate synthase and cytochrome oxidase c enzyme activity (in liver and skeletal muscle), body temperature and non-shivering thermogenesis. Our results support the model of allocation, which indicates commitments between metabolic rates and exploratory behavior, in a caloric restricted environment. Specifically, we identify the role of thermogenesis as a pivotal budget item, modulating the reallocation of energy between behavior and basal metabolic rate. We conclude that brown adipose tissue and liver play a key role in the development of paradoxical responses when facing decreased dietary availability.

Due to the finite nature of the energy budget, resource-limited conditions impose changes in the allocation of resources between competing processes, such as growth, reproduction and survival ${ }^{1,2}$. What an animal eats determines the nutrient intake and, ultimately, the distribution of resources between the above mentioned competing biological and physiological processes. Thus, physiological and behavioral traits influencing resource acquisition and use are those having a key effect on the fitness of an individual ${ }^{3}$. In order to maintain the energy balance animals often exhibit physiological adjustments when subjected to a decrease in resource availability. Among those adjustments, both reduction in the basal metabolic rate (BMR) and body temperature (e.g., depression of non-shivering thermogenic activity, NST), allow the resource allocation to other vital processes, in scenarios of energy reductions such as food restriction ${ }^{4-6}$. These responses to food deprivation, documented in various species of marsupial and eutherian mammals ${ }^{5,7-9}$, also entail a reduction of the body mass, metabolic expenditure and a decrease in behavioral activity ${ }^{10-12}$.

Yet, at least three species of rodents (e.g., Mus musculus, Cricetulus barabensis, Eothenomys miletus) present a behavioral response considered as "paradoxical" in the face of stochastic deprivation of food or when fed on low-energy diets ${ }^{13-17}$. Indeed, enlargement of the intestine (see ref. $\mathrm{in}^{18}$ ) and changes in behavioral patterns such as an increased locomotion and exploratory activities have been described ${ }^{4,14,17,19}$ and consequently, animals display markedly increased locomotor behavior as well as a decrease in basal metabolic rates and NST ${ }^{6}$. This paradox would imply an investment in structure and function, despite the lack and unpredictable variation of trophic resources. Some of the physiological and molecular mechanisms behind these responses have been identified,

${ }^{1}$ Departamento de Ciencias Ecológicas, Facultad de Ciencias, Universidad de Chile, Santiago, Chile. ${ }^{2}$ Laboratorio de Células troncales y Biología del Desarrollo, Departamento de Biología, Facultad de Ciencias, Universidad de Chile, Santiago, Chile. ${ }^{3}$ Postgrado Educación, Facultad de Humanidades, Universidad Mayor, Santiago, Chile. ${ }^{4}$ Center of Applied Ecology and Sustainability (CAPES), Pontificia Universidad Católica de Chile, Santiago, Chile. *email: vpalma@uchile.cl; psabat@uchile.cl 
whose magnitude appear to be modulated by the endocrine system through plasma variations in the concentrations of leptin and insulin that account for the energy status of the organism ${ }^{14,20-22}$.

Recent studies have evaluated the potential role of energetic constraints as drivers of consistent inter-individual differences in behavior ( $\operatorname{see}^{23}$ and references therein). The latter is in line with published evidence from food deprivation experiments, claiming that behavioral hyperactivity (shown as wheel running activity or time dedicated to different activities in home-cage behavior) is a function of the severity of food restriction. In this sense, differences among individuals in regards to variability of sources availability have been described, related both to the magnitude and direction of the association between exploratory activity and energy expenditure rates ( $\mathrm{see}^{24}$ for an example in birds), suggesting that a specific behavioral pattern, could be the result of given environmental conditions (see ${ }^{25}$, for a theoretical approach). Few researchers have addressed, however, the underlying mechanisms behind the relationship between exploratory behaviors and metabolic activity. For example, both features could express some of several relationships, such as trade-offs (e.g. does a limited budget imply a negative relationship between exploratory behaviors and metabolic rates?) or causality (e.g. is there a behavior- dependent modulation of metabolic rates? or vice versa $)^{24-26}$. To date, at least four theoretical models have been proposed to explain the functional association between behavioral traits and rates of energy expenditure ${ }^{26}$. In brief: (i) The allocation model, stating that a negative relationship between the rates of energy expenditure and physical activity is due to the existence of trade-offs in the allocation of resources to both processes; (ii) the performance model, postulating that a positive relationship between the variables emerges because individuals with higher metabolic rates would be able to invest more energy in locomotion activity, or, in other words, metabolic rates could determine the total energy available to an individual; (iii) the substitution model that establishes that in endothermic animals located below the lower critical temperature, the energy cost assigned to the behavior is reduced, and there would be no relationship between the rates of energy expenditure and physical activity. And finally, (iv) the independent model that suggests variation in basic energy requirements neither reduce nor increase the amount of energy available for other processes ${ }^{23,26,27}$.

Several studies support the idea that behavior and metabolism could be associated through mechanistic links. For example, in response to changes in the energy state of the organism, it has been reported that some liver proteins play a role in the modulation of locomotor behavior, such as FGF21 or IGF-I ${ }^{28,29}$. This response is often accompanied by variations in the levels of key metabolic enzymes, such as CS, revealing that its activity may be an indicator of liver function. In addition, skeletal muscles show an increase in their mitochondrial respiration under dietary restriction, which could hypothetically lead to an increment in their performance under a scenario of low food availability ${ }^{30}$.

Summarizing, the current evidence support that in some rodents stochastic food deprivation produces an increase in the frequency exploratory behavior (and/or of locomotion), coupled with a decrease in metabolic rates. Nevertheless, whether a trade-off between energetics and behavior does exist and to what extent this association is dependent on resource availability is less well defined. Thus, a challenging area in the field of behavioral and physiological ecology is the understanding of the causes and ecological consequences of the assumed functional association between maintenance costs and exploratory behavior or activity. This knowledge may shed light on these processes explaining the trade-offs related to the acquisition of energy (i.e., exploration, information and foraging) in different scenarios of resource availability.

The present paper aims to uncover and demonstrate the existence of trade-offs between physiological variables (e.g., BMR, NST, or mitochondrial activity) and behavioral responses when rodents are faced to stochastic deprivation of food and caloric restriction. To this end we developed an experiment, based on the study of the relationship of physiological and behavioral variables, choosing two factors; periodicity in feeding (continuous and stochastic) and caloric content of food (ad libitum and $60 \%$ of caloric restriction). Adult BALB/c mice were acclimatized for four weeks to these four feeding conditions followed by measurement of the following metabolic features: BMR (measured after treatment), temperature (along all treatment), non-shivering thermogenesis (measured one day after BMR), and mitochondrial activity of liver and skeletal muscle of hind limb legs. Besides, we measured as behavioral variables: the output of open field test or OFT (i.e., movement of individuals, measures before and after treatment) and home-cage behavior (i.e., time expended in to general activity, food, hygiene and rest behaviors, measured after treatment, before BMR measurements). Our results support the model of allocation, which indicates commitments between metabolic rates and exploratory behavior, in a caloric restricted environment.

\section{Results}

Exploratory behavior and physiological variables. In order to study behavioral effects of dietary restriction in mice first we examined the repeatability of behavioral traits in the OFT before and after the acclimation period. These calculations indicate that these traits are repeatable and are a good representation of an animal's behavior. Indeed, repeatability was 0.70 (IC: $0.45-0.84 ; \mathrm{p}<0.001$ ) for number of squares crossed in the OFT. Besides, Pearson correlation for pooled data was significant for the number of squares crossed in the open field, both after and before acclimation $\left(\mathrm{r}^{2}=0.319 ; \mathrm{r}=0.565 ; \mathrm{p}<0.001\right)$. Rodents acclimated to the stochastic feeding regime exhibited larger trajectories during the exploration test ( $\sim 12$ meters on average), in comparison with those fed continuously (factorial ANOVA $\mathrm{F}_{(1,39)}=0.098$, periodicity: $\mathrm{p}=0.010$, Fig. 1 ). In addition, there was a trend to form a negative relationship between the caloric intake of rodents and the number of squares crossed in the open field $\left(r^{2}=0.16, r=-0.400, p=0.072\right)$. In this line, a significant and negative association between the basal metabolic rate and the number of squares crosses was observed $\left(r^{2}=0.303 ; p=0.043\right.$, Fig. 2$)$, but not regarding mass-specific BMR.

We found a negative, although weak, relationship between the amount of squares crossed and the liver mass $\left(r^{2}=0.086, r=-0.293, p=0.048\right)$ and the spleen mass $\left(r^{2}=0.096, r=-0.309, p=0.041\right)$. 


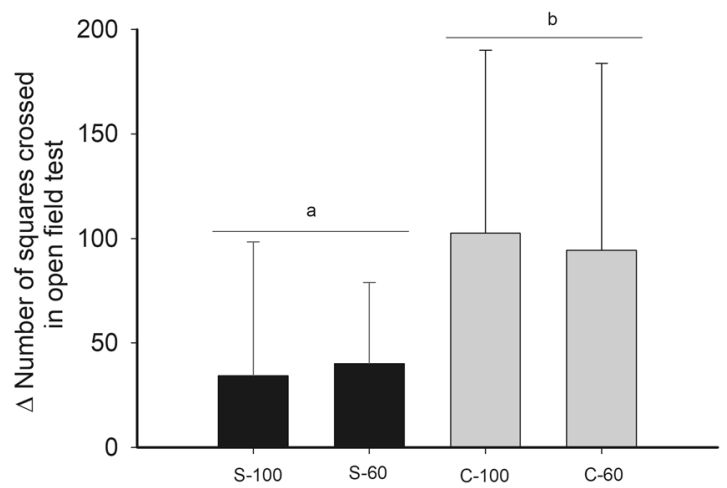

Figure 1. Effect of different food treatments on the trajectory covered in an open field test (number of squares crossed before acclimatization - number of squares crossed after acclimatization) in adult males BALB/c mice.

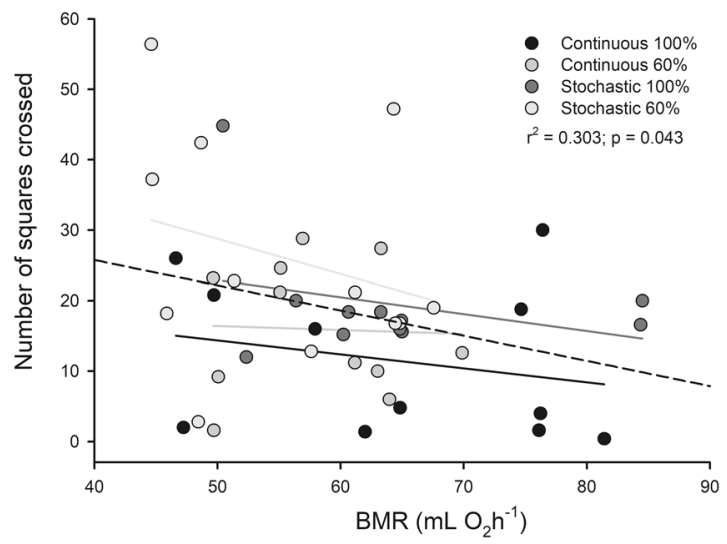

Figure 2. Relationship between basal metabolic rate and the number of squares crossed in an open field test, in adult males BALB/c mice after food treatments as indicated. Dashed line: linear regression for pooled data. There is no statistical significance by treatment.

Explanatory models (GLM) of exploratory activity were analyzed based on twenty physiological and anatomical variables and treatments (e.g., liver mass, residuals of liver mass, body mass, basal metabolic rate, minimal temperature, periodicity, etc.). Then, the interaction between these variables was analyzed and finally the best three models were selected. Specifically, the number of squares crossed was highly explained by reduction in the residuals of BAT, and affected by the interaction with periodicity and caloric intake. In a similar fashion, but in less degree, reductions in body mass also explained it. This behavioral variable was affected mainly by periodicity over caloric intake. All statistics are presented in Table 1.

Home-cage behavior and physiological variables. Individuals that allocated a high proportion of time to rest during the activity phase exhibited higher residual BMR, as well as higher mass-specific BMR when analyses were done in pooled data $\left(\mathrm{r}^{2}=0.233, \mathrm{r}=0.483, \mathrm{p}=0.001\right.$ and $\mathrm{r}^{2}=0.275, \mathrm{r}=0.524, \mathrm{p}<0.001$, respectively). However, when this association was evaluated per treatment, only in the stochastic groups these relationship were found to be significant for BMR $\left(r^{2}=0.466 ; r=0.682 ; p=0.030\right.$ and $r^{2}=0.485 ; r=0.696 ; p=0.017$, in S-60 and $\mathrm{S}-100$ respectively) and for residual BMR $\left(\mathrm{r}^{2}=0.409 ; \mathrm{r}=0.639 ; \mathrm{p}=0.046\right.$ and $\mathrm{r}^{2}=0.615 ; \mathrm{r}=0.784 ; \mathrm{p}=0.004$, in S-60 and S-100 respectively, Fig. 3). Also, a positive relationship between the percentage of time allocated to rest and residual of the liver mass was found when analyses were done in pooled data $\left(r^{2}=0.116, r=0.341, p=0.025\right.$, Fig. 4).

Regarding the time animals spent developing locomotor activity in their home-cages, we found a negative association between mass-specific BMR and percentage of general activity time when analyses were done in pooled data $\left(r^{2}=0.108 ; r=-0.329 ; p=0.033\right)$. But when this association was evaluated per treatment, only in the $\mathrm{S}-100$ group this relationship was found to be significant $\left(r^{2}=0.573 ; r=-0.757 ; p=0.007\right)$. Besides, a negative association between the proportion of time in which animals were found to be active and the hepatic activity of COX, was revealed when analyses were done in pooled data $\left(r^{2}=0.214, r=-0.462, p=0.026\right)$, Fig. 4. However, when this association was evaluated per treatment, only in S-100 and C-60 groups these relationship were found to be significant $\left(r^{2}=0.880, r=-0.938, p=0.006 ; r^{2}=0.769, r=-0.877, p=0.022\right.$, respectively), Fig. 4 .

As for the CS enzyme in the liver, only a trend in the negative relationship with the percentage of time in activity was observed $\left(\mathrm{r}^{2}=0.163, \mathrm{r}=-0.404, \mathrm{p}=0.056\right)$. 


\begin{tabular}{|c|c|c|c|c|c|c|}
\hline & $\begin{array}{l}\text { Response } \\
\text { variable }\end{array}$ & Models & Variables & Estimate & $\mathbf{P}$ & AIC \\
\hline \multirow{27}{*}{ Open Field Test } & \multirow{27}{*}{$\begin{array}{l}\text { Number of } \\
\text { squares crossed }\end{array}$} & \multirow{5}{*}{$\begin{array}{l}\text { Periodicity + Residuals } \\
\text { BAT * Body mass }\end{array}$} & Intercept & 7.11 & $* * *$ & \multirow{5}{*}{1835.5} \\
\hline & & & Periodicity & -0.43 & $* * *$ & \\
\hline & & & Residuals BAT & -8.26 & *** & \\
\hline & & & Body mass & -0.09 & $* * *$ & \\
\hline & & & Residuals BAT * Body mass & 0.31 & $* * *$ & \\
\hline & & \multirow{6}{*}{$\begin{array}{l}\text { Periodicity+Caloric } \\
\text { intake + Residuals BAT * } \\
\text { Body mass }\end{array}$} & Intercept & 7.16 & *** & \multirow{6}{*}{1826.4} \\
\hline & & & Periodicity & -0.45 & $* * *$ & \\
\hline & & & Caloric intake & -0.11 & $* * *$ & \\
\hline & & & Residuals BAT & -8.79 & $* * *$ & \\
\hline & & & Body mass & -0.08 & $* * *$ & \\
\hline & & & Residuals BAT * Body mass & 0.32 & $* * *$ & \\
\hline & & \multirow{16}{*}{$\begin{array}{l}\text { Periodicity * Caloric intake } \\
\text { * Residuals BAT * Body } \\
\text { mass }\end{array}$} & Intercept & 10.42 & **** & \multirow{16}{*}{1335.6} \\
\hline & & & Periodicity & -7.01 & $* * *$ & \\
\hline & & & Caloric intake & -6.30 & $* * *$ & \\
\hline & & & Residuals BAT & -56.48 & $* * *$ & \\
\hline & & & Body mass & -0.21 & $* * *$ & \\
\hline & & & Periodicity * Caloric intake & 7.77 & $* * *$ & \\
\hline & & & Caloric intake * Residuals BAT & 24.41 & ${ }^{*}$ & \\
\hline & & & Periodicity* Residuals BAT & 72.68 & **** & \\
\hline & & & Caloric intake $*$ Body mass & 0.23 & $* * *$ & \\
\hline & & & Periodicity * Body mass & 0.24 & $* * *$ & \\
\hline & & & Residuals BAT * Body mass & 2.08 & $* * * *$ & \\
\hline & & & $\begin{array}{l}\text { Periodicity* Caloric intake* } \\
\text { Residuals BAT }\end{array}$ & -113.91 & $* * *$ & \\
\hline & & & $\begin{array}{l}\text { Periodicity * Caloric intake* Body } \\
\text { mass }\end{array}$ & -0.26 & $* * *$ & \\
\hline & & & $\begin{array}{l}\text { Caloric intake* Residuals BAT* } \\
\text { Body mass }\end{array}$ & 1.10 & $* *$ & \\
\hline & & & $\begin{array}{l}\text { Periodicity *Residuals BAT* Body } \\
\text { mass }\end{array}$ & -2.60 & $* * *$ & \\
\hline & & & $\begin{array}{l}\text { Periodicity*Caloric } \\
\text { intake*Residuals BAT* Body mass }\end{array}$ & 4.44 & $* * *$ & \\
\hline \multirow{19}{*}{ Home-cage behavior } & \multirow{9}{*}{$\begin{array}{l}\text { Time in } \\
\text { general activity } \\
(\%)\end{array}$} & \multirow{3}{*}{$\begin{array}{l}\text { Body mass + mass-specific } \\
\text { BMR }\end{array}$} & Intercept & 53.58 & * & \multirow{3}{*}{363.89} \\
\hline & & & Body mass & 1.50 & * & \\
\hline & & & Mass-specific BMR & -12.00 & ${ }^{*}$ & \\
\hline & & \multirow{3}{*}{$\begin{array}{l}\text { Mass-specific } \\
\text { BMR + Epididymal WAT }\end{array}$} & Intercept & 85.44 & **** & \multirow{3}{*}{362.82} \\
\hline & & & Mass-specific BMR & -11.86 & . & \\
\hline & & & Epididymal WAT & 23.19 & ${ }^{*}$ & \\
\hline & & \multirow{3}{*}{$\begin{array}{l}\text { Epididymal } \\
\text { WAT + Minimal } \\
\text { temperature }\end{array}$} & Intercept & 100.92 & $* * *$ & \multirow{3}{*}{361.95} \\
\hline & & & Epididymal WAT & 25.96 & * & \\
\hline & & & Minimal temperature & -1.50 &. & \\
\hline & \multirow{10}{*}{$\begin{array}{l}\text { Time resting } \\
(\%)\end{array}$} & \multirow{3}{*}{$\begin{array}{l}\text { Residuals } \\
\text { BMR + Residuals liver }\end{array}$} & Intercept & 13.74 & **** & \multirow{3}{*}{326.49} \\
\hline & & & Residuals BMR & 0.56 & $* * *$ & \\
\hline & & & Residuals liver & 18.39 & * & \\
\hline & & \multirow{4}{*}{ Periodicity * BMR } & Intercept & -39.74 & $* *$ & \multirow{4}{*}{330.8} \\
\hline & & & Periodicity & 53.10 & ** & \\
\hline & & & BMR & 0.88 & $* * *$ & \\
\hline & & & Periodicity * BMR & -0.88 & *** & \\
\hline & & \multirow{3}{*}{$\begin{array}{l}\text { Minimal } \\
\text { temperature + Residuals } \\
\text { liver }\end{array}$} & Intercept & -35.45 & ${ }^{*}$ & \\
\hline & & & Minimal temperature & 1.78 & ** & 327.24 \\
\hline & & & Residuals liver & 19.60 & *** & \\
\hline
\end{tabular}

Table 1. This table describes the use of the generalized linear model for analyzing the influence of periodicity, caloric intake (as dummy variables), and the interaction between these factors and metabolic rate, temperature and body/organ mass on the exploratory and home-cage behavior. All non-significant interaction effects $(p>0.05)$ in the GLM analyses were removed to obtain the best-fitted model in each case. We choose the best three models by Akaike's information criterion (AIC). Abbreviation: BAT = Brown adipose tissue, $\mathrm{BMR}=\mathrm{Basal}$ metabolic rate, WAT $=$ White adipose tissue. Significance codes: 0 '***' $-0.001^{\prime} * *$ ' $-0.01^{\text {‘*’ }}-0.05^{\prime \prime}$. 

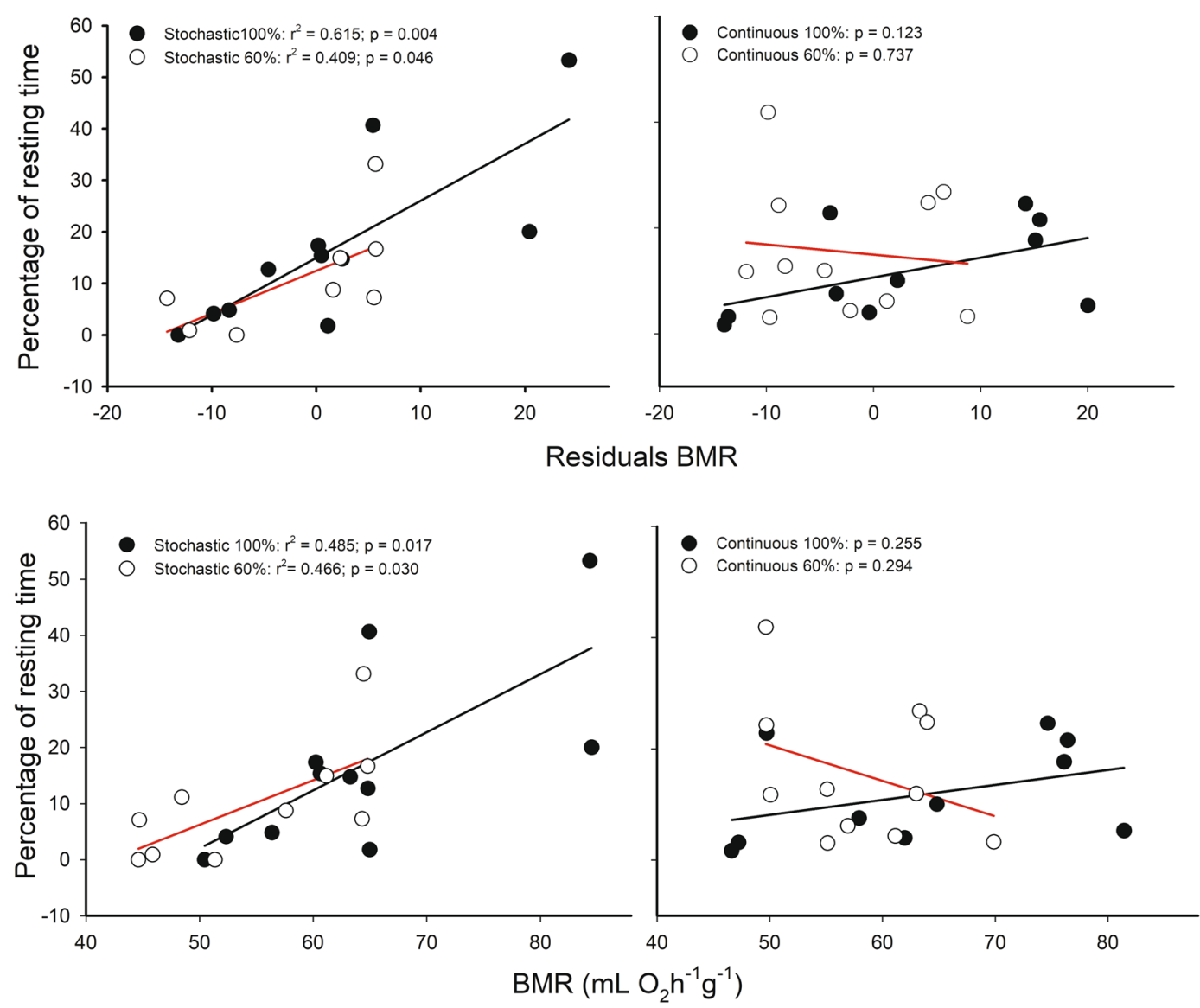

Figure 3. Relationships between energy expenditure rates corrected by body mass or BMR residuals versus body mass and the percentage of rest or inactivity time of Mus musculus individuals. Red lines indicate linear regression for mice under caloric restriction at $60 \%$, and black line ad libitum feeding.

The activity of rodents also was associated with changes in body temperature. In fact, when analyzing the whole data set, individuals with higher minimal and average dorsal skin temperatures, spent most of their time resting $\left(\mathrm{r}^{2}=0.202, \mathrm{r}=0.450, \mathrm{p}=0.003\right.$ and $\mathrm{r}^{2}=0.100 \mathrm{r}=0.316, \mathrm{p}=0.039$, respectively), Fig. 5 .

Regarding the origin of thermogenic activity, NST was positively correlated with dorsal skin temperatures of the individuals $\left(\mathrm{r}^{2}=0.128 ; \mathrm{r}=0.447 ; \mathrm{p}=0.037\right)$. When the analyses were done separating by experimental treatment, only the C-60 group revealed a negative association between NST and residuals of liver mass and time spent resting $\left(\mathrm{r}^{2}=0.862 ; \mathrm{r}=-0.928 ; \mathrm{p}=0.023\right.$ and $\mathrm{r}^{2}=0.838 ; \mathrm{r}=-0.915 ; \mathrm{p}=0.029$, respectively), Fig. 6 . These results are accompanied by the positive relation between BAT mass and percentage of time in activity found in these group $\left(r^{2}=0.457 ; r=0.676 ; p=0.023\right)$.

A positive relationship was found between the percentage of time devoted to feeding and citrate synthase activity of the hind limbs $\left(r^{2}=0.600, r=0.775, p<0.001\right)$. Likewise, individuals that showed a high activity of CS and COX, standardized by gram of proteins of the hind limbs, in turn showed greater displacements on the surface of the open field test $\left(\mathrm{r}^{2}=0.439, \mathrm{r}=0.662, \mathrm{p}<0.001\right.$ and $\mathrm{r}^{2}=0.338, \mathrm{r}=0.582, \mathrm{p}=0.003$, respectively), Fig. 7 .

Through GLM models, we found that the time spent in general activity, was related negatively with mass-specific BMR. However, epididymal WAT showed a positive relation with this behavioral feature. Interestingly, the time spent in resting was explained positively, mainly by residuals of liver against body mass. All statistics are presented in Table 1.

\section{Discussion}

The main objective of our study was to evaluate the effect of environmental food stochasticity and availability on selected physiological, biochemical and behavioral traits in a rodent model. Behavioral activity can be described as the levels of general activity of an individual in a familiar situation, while exploration is defined as the response of an individual to novel situations ${ }^{31}$. These behaviors are associated with foraging activity, territorial defense patrols, encounters of breeding pairs and habitat choices ${ }^{32,33}$. Exploration is also defined as the entire collection of seemingly unguided behaviors including movement through space, which is prompted by novel environments ${ }^{34}$. Previous studies suggested that higher activity and exploration capacity would increase the survival of organisms ${ }^{35}$.

In particular, organisms that dwell in unpredictable or unproductive environments will benefit from having an exploratory behavior and low basal metabolic rates since this would increase their probability of finding scarce 


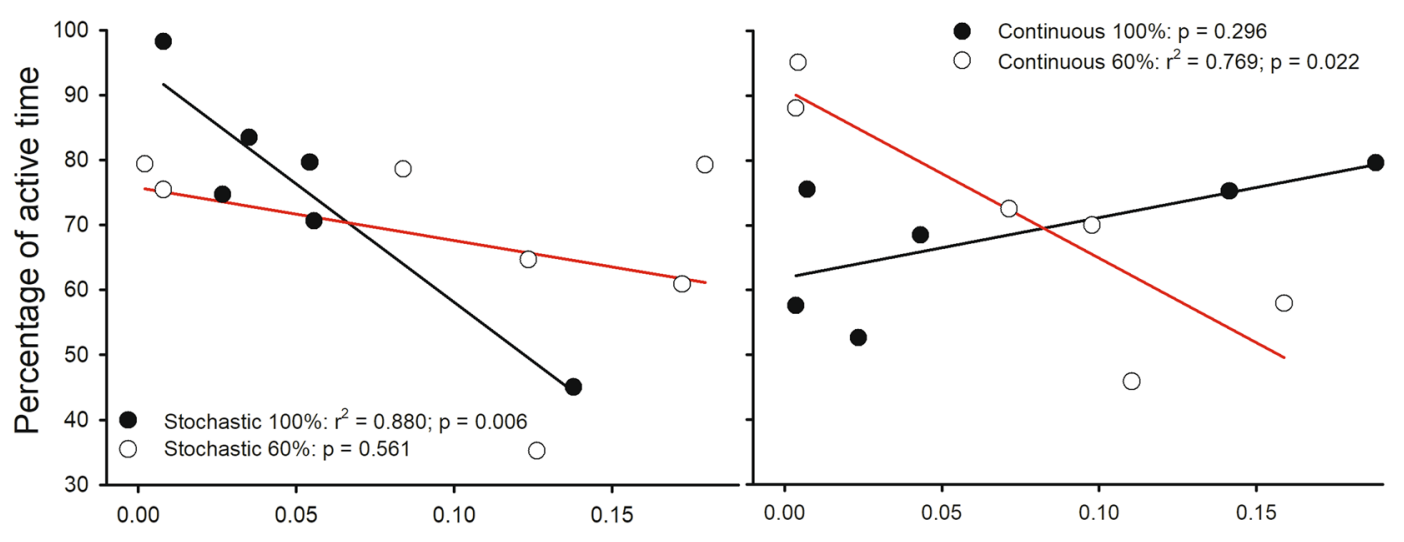

Liver COX activity ( $\mu \mathrm{mol} / \mathrm{min} \mathrm{mg}$ protein)

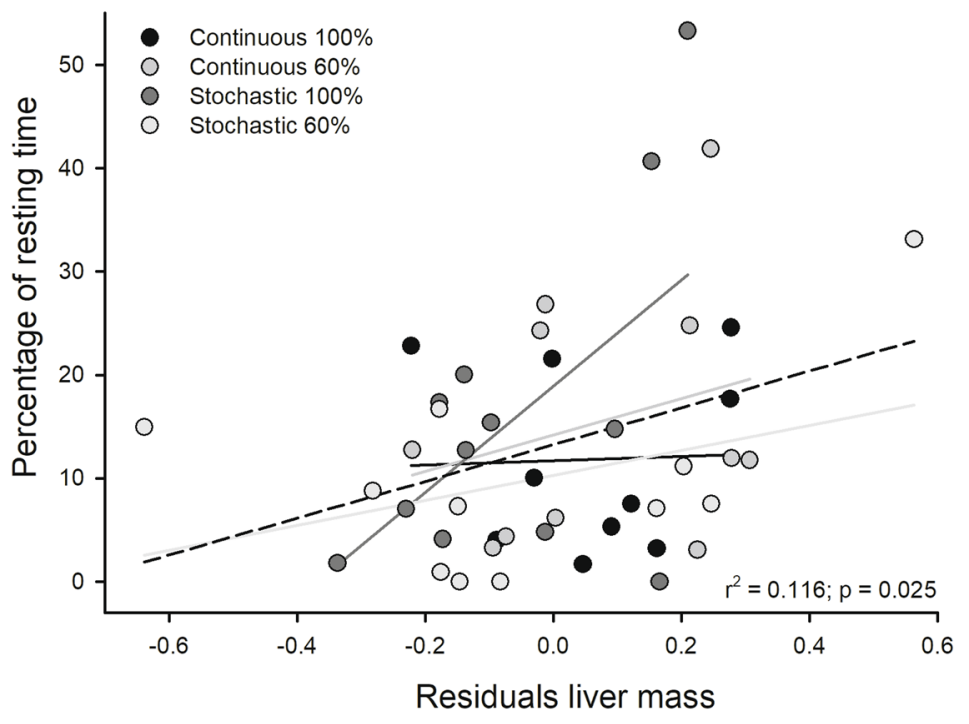

Figure 4. Relationships between liver and home-cage behavior, for mice acclimatized for four weeks to four food treatments: two caloric regimens (ad libitum and 60\% restriction) and two periodicities (continuous and stochastic). Upper panel show the association between percentages of time spent in locomotor activity and the enzymatic activity of cytochrome c oxidase from liver. Red lines indicate linear regression for mice under caloric restriction at $60 \%$, and black line ad libitum feeding. Below, liver residuals against body mass show a positive relation with percentage of time spent in resting. Dashed line: linear regression for pooled data. There is no statistical significance by treatment.

resources and, hence, survival during frequent resource shortages ${ }^{36}$. In this line, our results support the so-called allocation model ${ }^{27}$. Indeed, we consider that in the present experimental set up (mice under food restriction), the thermogenic activity was a budget item, which was affected by starvation, allowing the allocation of energy from metabolic rate to exploratory behavior.

Interestingly, our results confirm that behavioral repertories seem to respond differentially to environmental signal and conditions ${ }^{37}$. In the aforementioned study the trajectory was affected by periodicity but not by the food availability. In fact, the groups acclimatized to a stochastic feeding, presented a greater $\Delta_{t}$ in the exploration test than those acclimated to the continuous regime. Besides, our data reveal that individuals, who traveled the greatest distances, together, presented reductions in the BMR (see Fig. 2). These results strongly support the energy allocation model $\left(\mathrm{See}^{26,27}\right.$ ), in which a compromise between the rates of energy expenditure and the locomotion activity performed by individuals takes place. These findings are also supported by the analyses of GLM, which revealed a negative relationship between mass-specific BMR and time in general activity. Apparently, this relationship between metabolic rates and behavior will often be determined by genetic constrains but also be modulated by the environment. In this vein, by using an evolutionary experimental approach, some authors concluded that caloric restriction increased more strongly the spontaneous physical activity in laboratory mice divergently selected for low BMR, in comparison with a higher BMR line $\mathrm{e}^{38}$.

The analysis from home-cage behavior (i.e., their cages) leads to similar conclusions to those that come from the exploration tests. In this sense, it was found that individuals who spent most time in resting behavior had higher metabolic rates, supporting that energy condition caused by the access to resources would determine the 

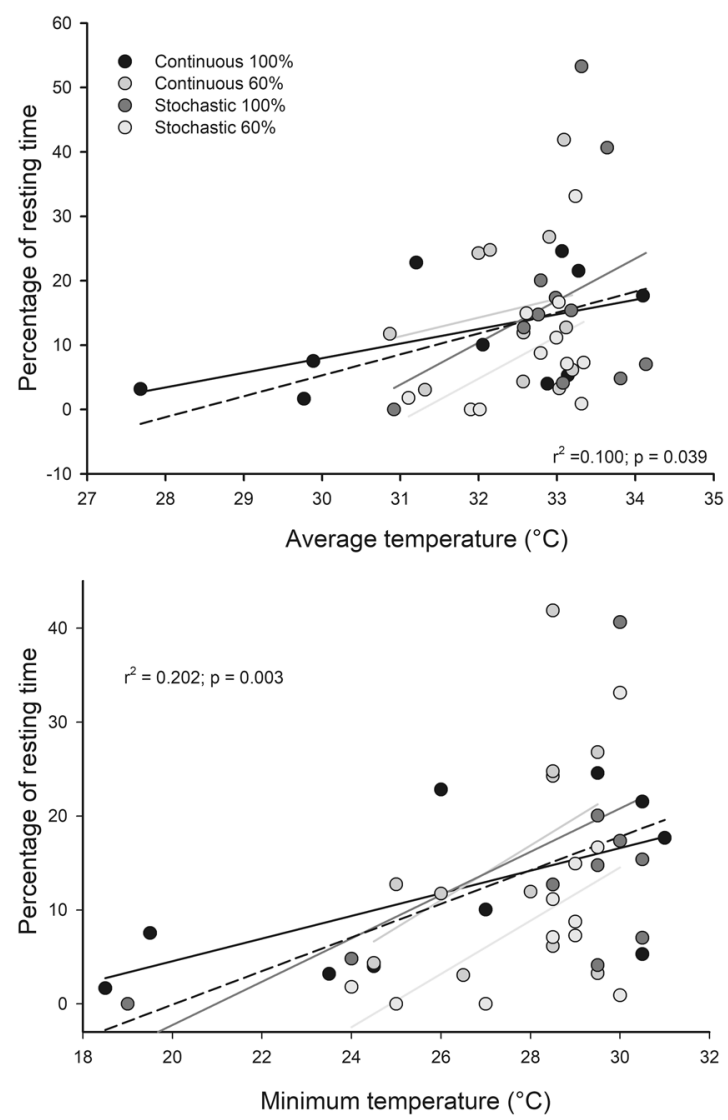

Figure 5. Relationships between surface skin temperatures and the percentage of rest or inactivity time of Mus musculus acclimatized for four weeks to four different food treatments. Dashed line: linear regression for pooled data. There is no statistical significance by treatment.

amount of energy allocated to energy maintenance and locomotion activity. Regarding this high locomotion activity, despite we do not observe a reduction in the activity, several studies indicate that sustaining high levels of activity under conditions of caloric restriction is not always possible. In fact, there would be biphasic responses, which would involve an increase in locomotive activity, followed by a chronic decrease ${ }^{39}$.

Role of liver. The results of maintenance energy expenditure rates along with behavioral experiments provide empirical support to the resource allocation model. However, what are the underlying mechanisms or the physiological basis that would be behind this phenomenon in the context of variation of food availability? Of note, it has been show that liver reduces its key metabolic enzyme activities due to the restriction of food intake ${ }^{40}$. Hence, this organ could be a key structure in the generation of the described trade-offs between metabolism and locomotor activity. This conclusion could be supported by evidence, which suggest that caloric restriction influences key metabolic enzyme activities (e.g., citrate synthase) ${ }^{41}$. Indeed, some studies have found that hepatic metabolism could modulate the locomotor behavior and temperature by means of a transcriptional regulation of FGF21 (a growth factor hormone produced mainly in the liver upon fasting and protein restriction) through mTORC1 (an energetic or nutritional sensor) ${ }^{29}$. This hormone might be involved in the adaptive response of body temperature to chronic starvation ${ }^{42}$ and is also implicated in feeding behavior ${ }^{43}$. Besides, there are evidences that suggest the role of liver-derived IGF-I (an anabolic hormone, insulin-like growth factor1) in the regulation of locomotor activity in mice $^{28}$, and in the hypothermic response to caloric restriction ${ }^{44}$. Then, all evidences indicate that several physiological pathways could link liver metabolism, behavior and temperature. In addition, our observation that the liver is as a key structure in the allocation hypothesis is supported by recognizing that the most active individuals in the scotophase have lower COX activities in liver tissue (see Fig. 4). This last observation, regarding catabolic abilities, is valuable in the context of understanding metabolic effects, since COX is an enzyme that directly participates in the reduction of oxygen inside the mitochondria ${ }^{45}$. In addition, this finding is relevant, considering that previous work has only focused on the change of organ masses, and failed to address biochemical adjustments to explain the relationships between metabolism and behavioral traits ${ }^{46}$.

Role of temperature and NST. From a bioenergetic perspective, the physiological adjustments developed by a caloric restriction would involve an allostatic energy challenge, where "set points" and other boundary of control may change with environmental conditions ${ }^{47}$. In line whit such definition, our data indicate changes in temperature regulation associated to modifications in behavior. Specifically, our results show an inverse relation between temperature variables (i.e., liver catabolism, skin temperature) and locomotor activity (i.e., percentage 

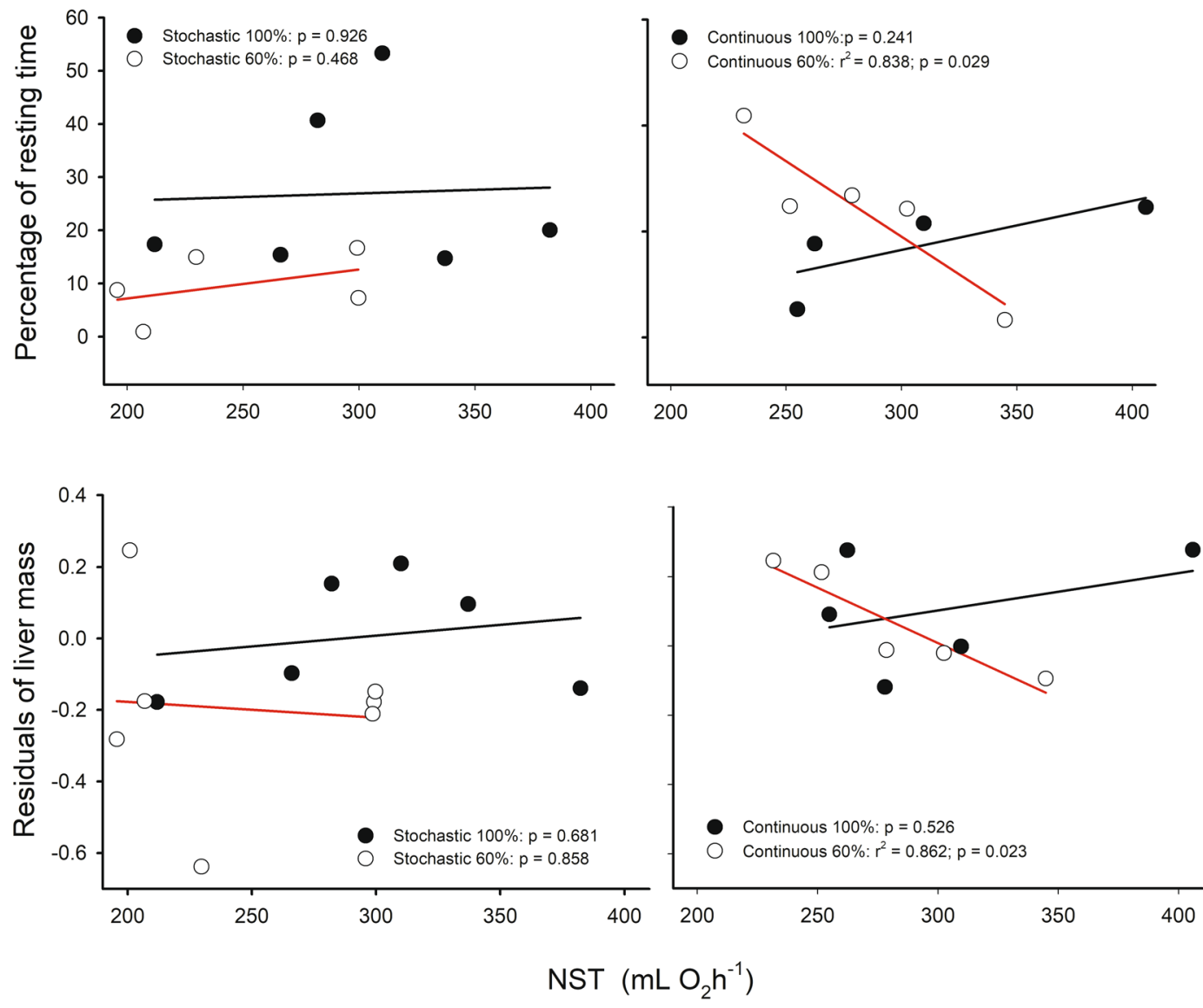

Figure 6. Relationships between home-cage behaviors or liver, and non-shivering thermogenesis, for mice acclimatized for four weeks to four food treatments. Upper panel shows the association between percentages of time spent in resting and the oxygen consumption under norepinephrine stimulation. Below, association between liver residuals against body mass and non-shivering thermogenesis. Red lines indicate linear regression for mice under caloric restriction at $60 \%$, and black line ad libitum feeding.

of activity time). Similar results have been found in multiple studies that address food stochasticity and caloric restriction in rodents ${ }^{16,48-55}$. This reduction of temperature is possible, since rodents are a group of homeotherms capable of lowering their body temperature below $31^{\circ} \mathrm{C}^{15}$ and even prefer colder temperatures than their thermoneutral zones ${ }^{56}$. This characteristic presented by rodents, entails their ability to develop thermoregulatory adjustments and suppress energy expenditure rates $\left(\mathrm{see}^{57}\right)$. In addition, it has been proposed that this could be a strategy that allows coping with adverse conditions, maximizing biological adequacy ${ }^{55}$.

Earlier studies have revealed a relation between brown BAT and cold acclimation. Specifically, BAT was identified as a thermogenic organ and shown to be the major site of thermoregulatory NST in rats acclimated to the $\operatorname{cold}^{58,59}$. Consequently, we find several negative associations between both BAT mass and NST, with behavioral and hepatic features. Indicating that NST could be compromising liver mass and behavior under caloric restriction. At the same time, more active individuals had lower temperatures, suggesting that a reallocation of energy from mitochondrial decoupling processes and hydrolysis of ATP, towards the development of locomotor activity might occur. In terms of mechanistic, we hypothesize that at tissular level molecular sensors of energy, such as mTOR or sirtuins, could modulate differential processes in the same individual. For example, oxidative activity occurring in on tissue, while anabolism or another energetically expensive process (e.g., locomotor activity) occurring in another ${ }^{60}$. From this "allocation" (or differential response to nutrient availability) an adaptive adjustment to caloric restriction by means of the restricted use of energy and biomolecules can result. The later could explain, at least partially, results obtained in several species of rodents. For instance ${ }^{6}$, have reported that, Mus musculus individuals maintained under an unpredictable feeding regime reduced their rates of energy expenditure and NST. In the same way, low-energy diets lead to a reduction in NST in Microtus brandtii and Meriones unguiculatus $^{61,62}$. Interestingly, the reallocation described here could depend on a genetic background even within intra-specific variability. In consequence, the magnitude of the responses presented here might not be universal for all rodents, considering that it has been documented that there are differences in the thermal and behavioral responses to caloric restriction between inbred mouse strains ${ }^{63}$.

Summary and future perspectives. In summary, our results support the allocation model, which indicates commitments between metabolic rates and exploratory behavior, in a caloric restricted environment. Specifically, we identified the role of thermogenesis as a pivotal budget item, in the modulation of reallocation of 

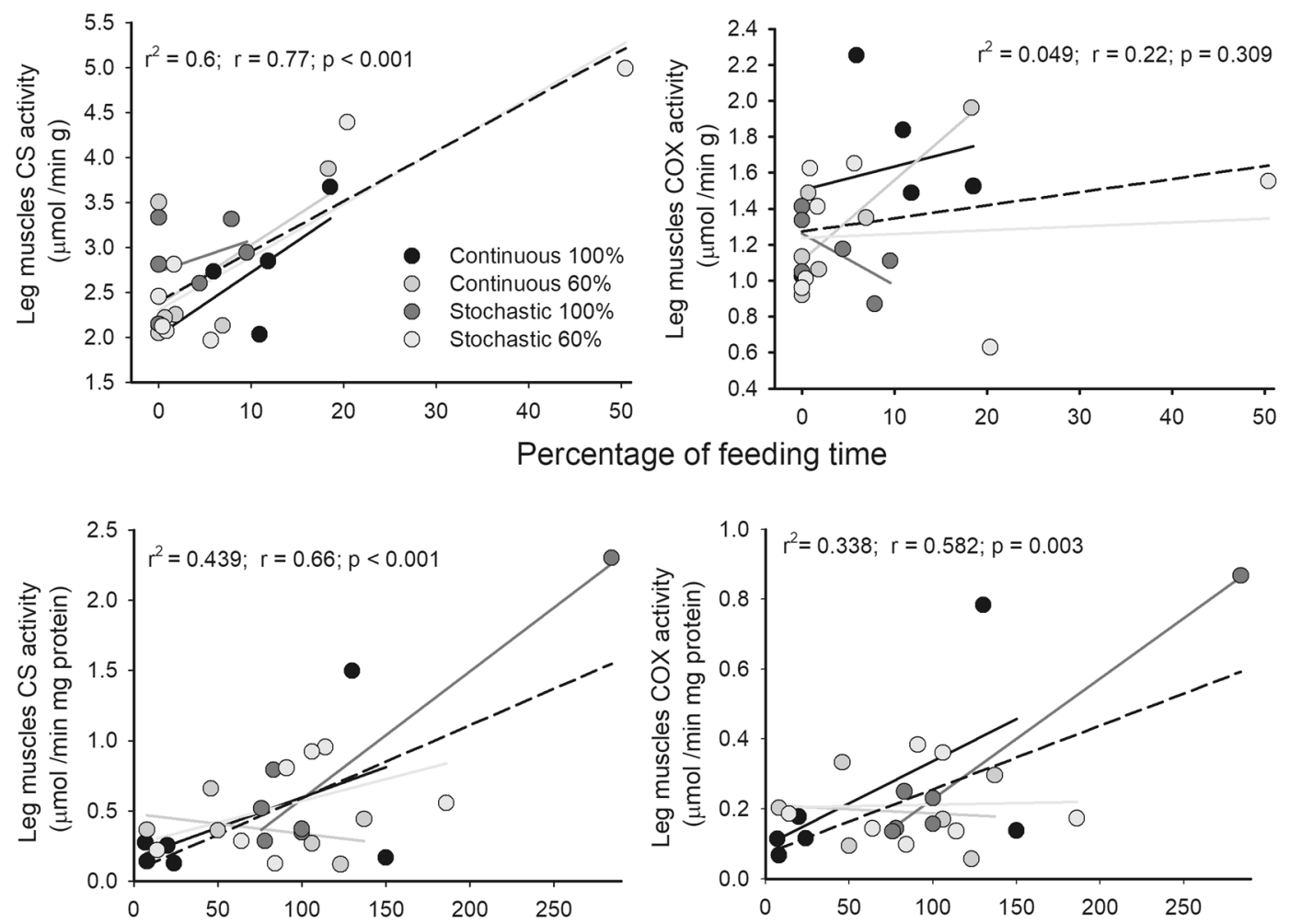

Number of squares crossed

Figure 7. Relationships between mitochondrial enzymes from leg muscles and home-cage or exploratory behavior, for mice acclimatized for four weeks to four food treatments. Upper panel shows the association between percentages of time spent in feeding and the citrate synthase (CS)/cytochrome c oxidase (COX) from leg muscles. Only stochastic $60 \%$ treatment shows a significant association for CS activity $\left(\mathrm{r}^{2}=0.840\right.$; $\mathrm{p}=0.01$ ). Below, show and positive association between CS/COX and squares crossed in open field test. In both analyzes, stochastic $100 \%$ group presented a significant association $\left(r^{2}=0.91 ; p=0.003\right.$ and $r^{2}=0.97 ; p<0.001$, respectively). Dashed line: linear regression for pooled data.

energy between behavior and BMR. We conclude that BAT and liver play a key role in the development of paradoxical responses to dietary availability constraints.

We propose that the physiological changes observed in Mus musculus in a caloric restricted environment could be a common phenomenon in rodents, and likely explain some of their invasive capacities in a strategy of energy allocation to favor an exploratory behavior. Even though the most of these responses have been studied in laboratory animals, we suggest that our results could be extrapolated to nature, under certain conditions. In fact, many studies indicate that laboratory rodents (rats and mice) show an increase in their activity under food deprivation, which is proportional to the severity of food restriction ${ }^{64}$. Because animals often face nutritional bottlenecks $^{65,66}$, it is not surprising that under these circumstances, the physiological and behavioral adjustments observed in the current study could occur in wild life.

Additionally, further studies about paradoxical response to caloric restriction should consider including the genetic and epigenetic contributions that drive intraspecific differences in response to food availability. Moreover, there could be an important contribution extending this analysis to several strains of Mus musculus or in mice under metabolic programming. Finally, a major remaining challenge in the field is how to combine these studies to changes in the expression profile of genes related to metabolism, heat production and behavior.

\section{Methods}

Animal acclimation. Forty-four adult males (3 months old) of the BALB/c strain of Mus musculus were obtained from the central animal housing facilities at the Faculty of Sciences, University of Chile. All animal procedures were in accordance with the Chilean legislation and were approved by Institutional Animal Care and Use Committees at the Universidad de Chile and Comisión Nacional de Investigación Científica y Tecnológica (CONICYT).

We design an experiment following ${ }^{18}$. Specifically, mice were separated into four groups of 11 animals each, considering no siblings in the same group. They were housed individually in mesh-floor cages without wood flakes, and kept at $25^{\circ} \pm 1^{\circ} \mathrm{C}$, in a $\mathrm{LD}=12: 12$ cycle, with water ad libitum. Mice had no access to their feces or to the small pieces of food $\left(<5 \mathrm{~mm}^{3}\right)$. Before initiating the experimental treatments, we measured the maximum food intake in a separate group of 10 males by locating animals individually inside of cages without wood flakes and with wastage of food. From those analyses, we recorded that food intake reaches a maximal value of $\sim 70 \mathrm{~g}$ 


\begin{tabular}{|l|l|l|l|}
\hline Treatment & $\begin{array}{l}\text { Food provision } \\
\text { (g/day) }\end{array}$ & $\begin{array}{l}\text { Food intake } \\
\text { range (g) }\end{array}$ & $\begin{array}{l}\text { Theoretical } \\
\text { requirements range (g) }\end{array}$ \\
\hline $\begin{array}{l}\text { Continuous alimentation with 60\% of } \\
\text { the ad libitum offer }\end{array}$ & 6 & $5.40-4.02$ & $4.96-4.10$ \\
\hline $\begin{array}{l}\text { Stochastic alimentation with 60\% of the } \\
\text { ad libitum offer }\end{array}$ & $14^{*}$ & $10.5-5.28$ & $5.08-3.83$ \\
\hline Continuous alimentation ad libitum & 10 & $7.37-3.69$ & $5.00-3.86$ \\
\hline Stochastic alimentation ad libitum & $23^{*}$ & $10.74-4.60$ & $4.88-3.83$ \\
\hline
\end{tabular}

Table 2. Summary of food provision and food intake values. Theoretical requirements were determined from metabolic estimates by means of the body mass (as indicated $\mathrm{in}^{80}$ ) and assuming a metabolizable energy of commercial pellet of $3.16 \mathrm{kcal} / \mathrm{g}$ (Prolab RMH 3000). Asterisk $\left(^{*}\right)$ indicate groups that fed three days by week, randomly assigned.

per week (Table 2). Based on these results, four experimental groups were acclimated during 20 days under the following conditions: (1) continual ad libitum food (C-100 treatment), with $10 \mathrm{~g}$ of dry food per day; these individuals could eat up to $70 \mathrm{~g}$ per week; (2) continual feeding with restriction at $60 \%$, with $6 \mathrm{~g}$ of dry food per day (C-60 treatment); these individuals could eat up to $42 \mathrm{~g}$ per week; (3) stochastic alimentation at $100 \%$ (S-100 treatment), with three random days of alimentation with $23 \mathrm{~g}$; these individuals could eat near to $70 \mathrm{~g}$ per week. Finally (4), stochastic alimentation with restriction at $60 \%$ (S-60 treatment) with 3 days of alimentation with $14 \mathrm{~g}$; these individuals could eat near to $42 \mathrm{~g}$ per week. All groups were fed with dried pellets of a commercial food (Prolab RMH 3000, Labdiet, USA).

Body temperature. In order to analyze the surface temperature of the animals during the whole acclimatization, a $3 \mathrm{~g}$ temperature data-logger (I-Buttons model DS1921L, Dallas Semi-conductors, USA) was installed on the back of each individual ${ }^{8,67}$. Sensors allowed us to register the skin temperature of the animals every 30 minutes for 20 days. After the animals were sacrificed (see below), the sensors were extracted and analyzed with the OneWireViewer software (0.3.17.44). Based on this information, the minimum, maximum and average body temperatures were calculated.

Metabolic measurements. Metabolic rates were estimated via oxygen consumption rate $\left(\mathrm{VO}_{2}\right)$ using a FoxBox respirometer (Sable Systems, Las Vegas, NV), following a modified protocol of ${ }^{24}$. Oxygen consumption was measured in 6-hours fasted animals using an illuminated chamber $(0.75 \mathrm{~L})$ located in a controlled temperature cabinet (Sable Systems, Henderson, Nevada) and kept at a constant ambient temperature within the thermoneutral zone for these species $\left(\mathrm{Ta}=30 \pm 0.5^{\circ} \mathrm{C}\right)$. During measurement of $\mathrm{BMR}$, we passed both incurrent and excurrent gas streams $\left(500 \mathrm{~mL} \mathrm{~min}^{-1}\right)$ through columns of Drierite and Baralyme to remove $\mathrm{H}_{2} \mathrm{O}$ and $\mathrm{CO}_{2}$. Output from the oxygen analyzer (\%) was digitalized using a Universal Interface II (Sable Systems) and recorded using EXPEDATA data acquisition software (Sable Systems). Our sampling interval was $5 \mathrm{~s}$. All measurements were made during the resting phase (09:00 and 15:00 h). Oxygen consumption was calculated according to ${ }^{68}$ and $\mathrm{BMR}$ was estimated as the average lowest oxygen consumption, under a stable register form 300 samples ( $25 \mathrm{~min})$.

Non-shivering thermogenesis. In order to analyze the thermogenic capacities independent of muscular activity, the NST was measured by the administration of norepinephrine (norepinephrine bitartrate, Sigma-Aldrich) and the subsequent oxygen consumption record. For this, the metabolic rate was recorded for one hour at $25^{\circ} \mathrm{C}$ in an open respirometry system, and then approximately $0.02 \mathrm{mg}$ of norepinephrine was administered in a volume of $100 \mu \mathrm{L}^{69}$, by means of a suprascapular subcutaneous injection to each individual. Finally, the oxygen consumption after the injection was recorded for one hour at $25^{\circ} \mathrm{C}^{70}$.

Home-cage behavior. Home-cage behavior (i.e., cages where the individuals were acclimatized) was analyzed at the end of the acclimatization. In short, the rodents were filmed for 10 minutes, in the activity phase (21:00 to 2:00) in absolute darkness. The records were made using an infrared camera (Wanscam HW0026) located 1.5 meters above the cages on an articulated support. The camera was connected to a personal computer, arranged in an adjoining room, where filming was recorded. Subsequently, the behaviors present in the filming were analyzed through BORIS software (Behavioral Observation Research Interactive Software) ${ }^{71}$, quantifying the time allocated to four categories: general activity, food, hygiene and rest behaviors ${ }^{72}$.

Exploratory behavior. The exploratory behavior was assessed through an open field test ${ }^{36}$ both at the beginning and end of the acclimation period. To this end, a square acrylic box (thickness of $2 \mathrm{~mm}$ ) of white color was used, with an internal surface of $1 \mathrm{~m}^{2}$ and a height of $30 \mathrm{~cm}$. These measurements were recorded within the activity phase of the species (21:00 to 02:00) as briefly described: at the beginning of the measurement the rodents were placed in the center of the field and for 10 minutes they were filmed in darkness using an infrared camera (Wanscam HW0026) located 2 meters above the exploration sand, in an articulated support. The camera was connected to a personal computer, arranged in an adjoining room where filming was recorded. Between each session the soil surface was completely cleaned with $70 \%$ ethanol. Running or walking are considered as an exploration index ${ }^{73}$, therefore, as a proxy of exploration or trajectory, we measured the number of squares crossed in the open field (internal surface of $1 \mathrm{~m}^{2}$, was digitally sectioned in a grid of 25 squares of $0.2 \times 0.2 \mathrm{~m}$ ). Then, we measured delta of trajectory in the exploration test (i.e., $\Delta_{t}=$ number of squares crossed before acclimatization - number of 
squares crossed after acclimatization). $\Delta \mathrm{t}$ was calculated to analyze the change in the magnitude of the displacement of mice in OFT, considering that food deprivation treatments could increase the exploratory behavior of individuals. Video analysis was performed with Phobos software ${ }^{74}$.

After all measurements, animals were sacrificed by cervical dislocation, then liver and fat deposits were weighed ( $\pm 0.001 \mathrm{~g}$; Analytical Balance, AUX Series, Shimadzu Scientific Instruments) i.e., brown adipose tissue (BAT), epididymal, and inguinal fat pads. Besides, immediately after its sacrifice, the liver and the musculature present in the hind legs (biceps femoris, gracilis, semitendinosus, rectus femoris, anterior tibialis and vastus lateralis) were dissected on ice. The tissues were stored at $-80^{\circ} \mathrm{C}$, pending the completion of enzymatic assays.

Metabolic enzymes. The enzymatic activity determinations were carried out using hind legs muscles and liver tissue homogenates. Samples were homogenized on ice $(1: 10 \mathrm{w} / \mathrm{v})$ in phosphate buffer $0.1 \mathrm{M}$ supplemented with $2 \mathrm{mM}$ EDTA (pH 7.3) using an Ultra Turrax homogenizer $(20000 \mathrm{rpm})$. The samples were then sonicated at $130 \mathrm{~W}$ using an Ultrasonic Processor VCX 130 on ice 14 times in 20-second cycles and 10-second interval between cycles. Homogenates were then centrifuged at $15,000 \mathrm{rpm}$ for $15 \mathrm{~min}$ at $4^{\circ} \mathrm{C}$ to obtain a post mitochondrial fraction. The supernatant was transferred into a new tube, to avoid transferring the upper lipid layer present in the homogenates. Protein concentration was determined using the method by ${ }^{75}$ with bovine serum albumin as the standard. We measured the activity of two mitochondrial enzymes: cytochrome c oxidase (COX; E.C. 1.9.3.1) and citrate synthase (CS; E.C. 4.1.3.7). An increase in the activity of these enzymes likely reflects changes in both the functional properties and the density of mitochondria. The COX activity was quantified using a microplate spectrophotometric method slightly modified from that reported by ${ }^{76}$. In brief, enzyme activity was determined in a reaction mixture containing $10 \mathrm{mM}$ Tris $-\mathrm{HCl}(\mathrm{pH} 7), 120 \mathrm{mM} \mathrm{KCl}, 250 \mathrm{mM}$ sucrose, and cytochrome $\mathrm{c}$ reduced with dithiothreitol in a final volume of $0.2 \mathrm{ml}$. The decrease in extinction at $550 \mathrm{~nm}$ was monitored in a Thermo Scientific Multiskan GO UV/VIS spectrophotometer at $25^{\circ} \mathrm{C}$. Enzyme activity was calculated using an extinction coefficient of $21.84 \mathrm{mM}^{-1} \mathrm{~cm}^{-1}$ at $550 \mathrm{~nm}$ for cytochrome-c. The CS activity was measured according to ${ }^{77}$ with slight modifications. The enzyme assay medium contained $10 \mathrm{mM}$ Tris- $\mathrm{HCl}$ ( $\mathrm{pH} 8.0), 10 \mathrm{mM} 5,5^{\prime}$ dithiobis- (2 nitrobenzoic acid), $30 \mathrm{mM}$ acetyl Coenzyme $\mathrm{A}$ (acetyl CoA) and $10 \mathrm{mM}$ oxaloacetic acid (OAA) in a final volume of $0.2 \mathrm{ml}$; these reagents were omitted in controls. Citrate synthase catalyzes the reaction between acetyl CoA and OAA to form citric acid. The increase in extinction at $412 \mathrm{~nm}$ was measured in a Thermo Scientific Multiskan GO at $25^{\circ} \mathrm{C}$. Enzyme activity was calculated using an extinction coefficient of $13.6 \mathrm{mM}^{-1} \mathrm{~cm}^{-1}$ at $412 \mathrm{~nm}$. All enzyme activities are reported as specific activity per gram of protein $\left(\mu \mathrm{mol} \mathrm{min} \mathrm{mg}^{-1} \mathrm{mrotein}^{-1}\right)$.

Statistical analysis. The averages of the morphological, biochemical and behavioral variables of the different treatments were compared through one-way ANOVA and factorial ANOVA. In cases in which the variables correlated with the body mass, the residuals of each variable against body mass were used for the regression analyzes. In addition, the existence of possible associations between the variables related to rates of energy expenditure and those variables related to exploration and general activity was evaluated by means of Pearson correlations.

Repeatability analysis was performed for exploratory behavior at the beginning and end of acclimation. Intraclass correlation coefficient (ICC) was used for the analysis through a two-way mixed effects, consistency, and multiple measurement. Interpretation was as follows: $<0.50$, poor; between 0.50 and 0.75 , fair, between 0.75 and 0.90 good; above 0.90 , excellent ${ }^{78}$.

We used Generalized Linear Modeling (GLM) to test the influence of periodicity, caloric intake (as dummy variables), and the interaction between these factors and metabolic rate, temperature and body/organ mass on the exploratory and home-cage behavior. All non-significant interaction effects ( $p>0.05)$ in the GLM analyses were removed to obtain the best-fitted model in each case. We selected three models by behavioral variable, which best fitted our data by selecting the model that yielded the lowest Akaike's information criterion, AIC ${ }^{79}$. All statistical analyses were performed using the $\mathrm{R}$ statistical environment version 3.6.1.

Received: 17 October 2019; Accepted: 20 December 2019;

Published online: 05 March 2020

\section{References}

1. Boggs, C. L. Resource allocation: exploring connections between foraging and life history. Funct. Ecology. 6, 508-518 (1992).

2. English, S. \& Bonsall, M. B. Physiological dynamics, reproduction-maintenance allocations, and life history evolution. Ecol. Evolution 9, 9312-9323 (2019).

3. Karasov, W. H. \& del Rio, C. M. Physiological ecology: how animals process energy, nutrients, and toxins. (Princeton University Press, 2007).

4. Severinsen, T. \& Munch, I. C. Body core temperature during food restriction in rats. Acta Physiol. Scand. 165, 299-305 (1999).

5. Wang, T., Hung, C. C. \& Randall, D. J. The comparative physiology of food deprivation: from feast to famine. Annu. Rev. Physiol. 68, 223-251 (2006)

6. Cao, J., Zhang, L. \& Zhao, Z. Trade-off between energy budget, thermogenesis and behavior in Swiss mice under stochastic food deprivation. J. Therm. Biol. 34, 290-298 (2009).

7. Bozinovic, F. \& Méndez, M. A. Role of dietary fatty acids on energetics and torpor in the chilean mouse-opossum Thylamys elegans. Comp. Biochem. Physiol. 116A, 101-104 (1997).

8. Bozinovic, F., Muñoz, J. L. P., Naya, D. E. \& Cruz-Neto, A. P. Adjusting energy expenditures to energy supply: food availability regulates torpor use and organ size in the chilean mouse-opossum Thylamys elegans. J. Comp. Physiol. B Biochem. Syst. Env. Physiol. 177, 393-400 (2007).

9. Bozinovic, F., Ruiz, G. \& Rosenmann, M. Energetics, thermoregulation and torpor in the chilean mouse-opossum Thylamys elegans (Didelphidae). Rev. Chil. Hist. Nat. 78, 199-206 (2005).

10. Karasov, W. H. \& Diamond, J. M. Adaptive regulation of sugar and amino acids transport by vertebrate intestine. Am. J. Physiol. 245, G443-G462 (1983).

11. Carey, H. V. Gastrointestinal responses to fasting in mammals: lessons from hibernators. In: Starck, J. M. \& Wang, T. (eds) Physiological and ecological adaptations to feeding in vertebrates. (Science Publishers, 2005). 
12. Naya, D. E. \& Bozinovic, F. The role of ecological interactions on the physiological flexibility of lizards. Funct. Ecol. 20, 601-608 (2006).

13. Zhao, Z. J., Chen, K. X., Liu, Y. A., Wang, C. M. \& Cao, J. Decreased circulating leptin and increased neuropeptide Y gene expression are implicated in food deprivation-induced hyperactivity in striped hamsters, Cricetulus barabensis. Horm. Behav. 65, 355-362 (2014).

14. Hebebrand, J. et al. Hyperactivity in patients with anorexia nervosa and in semistarved rats: evidence for a pivotal role of hypoleptinemia. Physiol. Behav. 79, 25-37 (2003).

15. Overton, J. M. \& Williams, T. D. Behavioral and physiologic responses to caloric restriction in mice. Physiol. Behavior. 81, 749-54 (2004).

16. Zhao, Z. J. \& Cao, J. Plasticity in energy budget and behavior in Swiss mice and striped hamsters under stochastic food deprivation and refeeding. Comp. Biochem. Physiol. A. 154, 84-91 (2009).

17. Zhu, W. L. Y., Mu, H., Zhang, W. R., Gao, L. \& Zhang, Z. K. Wang. Effects of random food deprivation on body mass, behavior and serum leptin levels in Eothenomys miletus (Mammalia: Rodentia: Cricetidae). Italian J. Zoology. 81, 227-234 (2014).

18. Peña-Villalobos, I., Casanova-Maldonado, I., Lois, P., Sabat, P. \& Palma, V. Adaptive physiological and morphological adjustments mediated by intestinal stem cells in response to food availability in mice. Frontiers in physiology, 9 (2018)

19. Zhang, L. N. et al. Physiological and behavioral responses to intermittent starvation in C57BL/6J mice. Physiol. Behavior. 105, 376-387 (2012).

20. Asakawa, A. et al. Ghrelin is an appetite-stimulatory signal from stomach with structural resemblance to motilin. Gastroenterology. 120,337-345 (2001).

21. Holtkamp, K., Hebebrand, J. \& Herpertz-Dahlmann, B. The contribution of anxiety and food restriction on physical activity levels in acute anorexia nervosa. Int. J. Eat. Disord. 36, 163-171 (2004).

22. Jensen, T. L., Kiersgaard, M. K., Sørensen, D. B. \& Mikkelsen, L. F. Fasting of mice: a review. Laboratory Animals. 47, 225-240 (2013).

23. Mathot, K. J. \& Dingemanse, N. J. Energetics and behavior: unrequited needs and new directions. Trends Ecol. evolution. 30, 199-206 (2015).

24. Maldonado, K., van Dongen, W. F. D., Vásquez, R. A. \& Sabat, P. Geographic Variation in the Association between Exploratory Behavior and Physiology in Rufous-Collared Sparrows. Physiol. Biochem. Zool. 85, 618-624 (2012).

25. Houston, A. I. Evolutionary models of metabolism, behaviour and personality. Proc. R. Soc. Lond. [Biol]. 365, 3969-3975 (2010).

26. Careau, V. \& Garland, T. Jr. Performance, personality, and energetics: correlation, causation, and mechanism. Physiol. Biochem. Zool. 85, 543-571 (2012).

27. Careau, V., Thomas, D., Humphries, M. M. \& Réale, D. Energy metabolism and animal personality. Oikos. 117, 641-653 (2008).

28. Svensson, J., Soderpalm, B., Sjogren, K., Engel, J. \& Ohlsson, C. Liver-derived IGF-I regulates exploratory activity in old mice. Am. J. Physiol. Endocrinol. Metab. 289, E466-E473 (2005)

29. Cornu, M. et al. Hepatic mTORC1 controls locomotor activity, body temperature, and lipid metabolism through FGF21. PNAS 111, 11592-11599 (2014).

30. Hempenstall, S., Page, M. M., Wallen, K. R. \& Selman, C. Dietary restriction increases skeletal muscle mitochondrial respiration but not mitochondrial content in C57BL/6 mice. Mech. Ageing Dev. 133, 37-45 (2012).

31. Le Galliard, J. F., Paquet, M., Cisel, M. \& Montes-Poloni, L. Personality and the pace-of-life syndrome: Variation and selection on exploration, metabolism and locomotor performances. Funct. Ecol. 27, 136-144 (2013).

32. Réale, D., Reader, S. M., Sol, D., McDougall, P. T. \& Dingemanse, N. J. Integrating animal temperament within ecology and evolution. Biol. Rev. 82, 291-318 (2007).

33. Biro, P. A. \& Stamps, J. A. Are animal personality traits linked to life-history productivity? Trends Ecol. Evol. 23, 361-368 (2008).

34. Alyan, S. \& Jander, R. Exploration is sufficient but not necessary for navigation with landmarks in the house mouse (Mus musculus). Learn. Motiv. 28, 558-576 (1997).

35. Smith, B. R. \& Blumstein, D. T. Fitness consequences of personality: a meta-analysis. Behav. Ecol. 19, 448-455 (2008).

36. Careau, V., Bininda-Emonds, O. R. P., Thomas, D. W., Réale, D. \& Humphries, M. M. Exploration strategies map along fast-slow metabolic and life-history continua in muroid rodents. Funct. Ecology. 23, 150-156 (2009).

37. Wong, B. \& Candolin, U. Behavioral responses to changing environments. Behav. Ecol. 26, 665-673 (2015).

38. Brzęk, P., Gębczyński, A. K., Książek, A. \& Konarzewski, M. Effect of calorie restriction on spontaneous physical activity and body mass in mice divergently selected for basal metabolic rate (BMR). Physiol. Behavior. 161, 116-122 (2016).

39. Speakman, J. R. \& Mitchell, S. E. Caloric restriction. Mol. Asp. Med. 32, 159-221 (2011).

40. Brown, J. C. L. \& Staples, J. F. Mitochondrial metabolism during fasting-induced daily torpor in mice. BBA - Bioenergetics. 1797, 476-486 (2010)

41. Hagopian, K., Hoo, R. S., López-Domínguez, J. A. \& Ramsey, J. J. Calorie restriction influences key metabolic enzyme activities and markers of oxidative damage in distinct mouse liver mitochondrial sub-populations. Life Sci. 93, 941-948 (2013).

42. Oishi, K. et al. FGF21 is dispensable for hypothermia induced by fasting in mice. Neuroendocrinol. Lett. 31, 198-202 (2010).

43. Hill, C. M. et al. FGF21 Signals Protein Status to the Brain and Adaptively Regulates Food Choice and Metabolism. Cell rep. 27, 2934-2947 (2019).

44. Cintron-Colon, R. et al. Insulin-like growth factor 1 receptor regulates hypothermia during calorie restriction. PNAS 114, 9731-9736 (2017).

45. Brunori, M., Giuffre, A. \& Sarti, P. Cytochrome c oxidase, ligands and electrons. J. Inorg. Biochemistry. 99, 324-336 (2005).

46. Mitchell, S. E. et al. The effects of graded levels of calorie restriction: III. Impact of short term calorie and protein restriction on mean daily body temperature and torpor use in the C57BL/6 mouse. Oncotarget. 6, 18314 (2015).

47. Fink, G. (Ed.) Stress science: neuroendocrinology. (Academic Press, 2010).

48. Weindruch, R., Kirstie, J. A., Cheney, K. E. \& Walford, R. L. Influence of controlled dietary restriction on immunologic function and aging. Federation proceedings. 38, 2007-2016 (1979).

49. Cheney, K. E. et al. The effect of dietary restriction of varying duration on survival, tumor patterns, immune function, and bodytemperature in B10C3F1 female mice. J. Gerontology. 38, 420-430 (1983).

50. Duffy, P. H., Feuers, R., Nakamura, K. D., Leakey, J. \& Hart, R. W. Effect of chronic caloric restriction on the synchronization of various physiological measures in old female Fischer-344 rats. Chronobiology International. 7, 113-124 (1990a).

51. Duffy, P. H., Feuers, R. J. \& Hart, R. W. Effect of chronic caloric restriction on the circadian regulation of physiological and behavioral variables in old male B6C3F1 mice. Chronobiology International. 7, 291-303 (1990b).

52. Weindruch, R., Kayo, T., Lee, C. K. \& Prolla, T. A. Gene expression profiling of aging using DNA microarrays. Mech. Ageing Dev. 123, 177-193 (2002)

53. Ferguson, M., Sohal, B. H., Forster, M. J. \& Sohal, R. S. Effect of long-term caloric restriction on oxygen consumption and body temperature in two different strains of mice. Mech. Ageing Dev. 128, 539-545 (2007).

54. Carrillo, A. E. \& Flouris, A. D. Caloric restriction and longevity: effects of reduced body temperature. Ageing Res. Rev. 10, 153-162 (2011).

55. Lusseau, D. et al. The effects of graded levels of calorie restriction: IV. Non-linear change in behavioural phenotype of mice in response to short-term calorie restriction. Sci. Rep. 5, 13198 (2015).

56. Gordon, C. J. Temperature regulation in laboratory rodents. (Cambridge Univ. Press. 1993).

57. Swan, H. Thermoregulation and bioenergetics. (Elsevier, 1974)

58. Smith, R. E. \& Horwitz, B. A. Brown fat and thermogenesis. Physiological Reviews. 49, 330-425 (1969).

59. Trayhurn, P. Origins and early development of the concept that brown adipose tissue thermogenesis is linked to energy balance and obesity. Biochimie. 134, 62-70 (2017). 
60. Chen, D. et al. Tissue-specific regulation of SIRT1 by calorie restriction. Genes. Dev. 22, 1753-1757 (2008).

61. Zhang, L. \& Wang, D. Effects of food restriction and refeeding on energy balance regulation in Mongolian gerbils (Meriones unguiculatus). Appetite. 3, 758 (2008).

62. Zhao, Z. J. \& Wang, D. H. Effects of diet quality on energy budgets and thermogenesis in Brandt's voles. Comp. Biochem. Physiol. 148, A168-A177 (2007).

63. Gelegen, C., Collier, D. A., Campbell, I. C., Oppelaar, H. \& Kas, M. J. H. Behavioral, physiological, and molecular differences in response to dietary restriction in three inbred mouse strains. Am. J. Physiol. Endocrinol. Metab. 291, 574-581 (2006).

64. Morse, A. D. et al. Diurnal variation of intensive running in food-deprived rats. Can. J. Physiol. Pharmacol. 73, 1519-1523 (1995).

65. Karasov, W. H. Nutritional bottleneck in a herbivore, the desert wood rat (Neotoma lepida). Physiol. Zool. 62, 1351-1382 (1989).

66. Sassi, P. L., Borghi, C. E., Dacar, M. A. \& Bozinovic, F. Geographic and seasonal variability in feeding behaviour of a small herbivorous rodent. Acta Theriol. 56, 35-43 (2011).

67. Brown, K. J. \& Downs, C. T. Seasonal patterns in body temperature of free-living rock hyrax (Procavia capensis). Comp. Biochem. Physiol, Part. A: Mol. Integr. Physiol. 143, 42-49 (2006).

68. Withers, P. C. Measurement of $\mathrm{VO}_{2}, \mathrm{VCO}_{2}$, and evaporative water loss with a flow-through mask. J. Appl. Physiol. 42, 120-123 (1977).

69. Wunder, B. A. \& Gettinger, R. D. Effects of body mass and temperature acclimation on the nonshivering thermogenic response of small mammals. Pp. 131-139 In F. Geiser, A. J. Hulbert and S. C. Nicol, eds. Adaptations to the Cold: Tenth International Hibernation Symposium. 1st ed. (University of New England Press, 1996)

70. Zhu, W. L., Jia, T., Lian, X. \& Wang, Z. K. Effects of cold acclimation on body mass, serum leptin level, energy metabolism and thermognesis in Eothenomys miletus in Hengduan Mountains region. J. Therm. Biol. 35, 41-46 (2010).

71. Friard, O. \& Gamba, M. BORIS: a free, versatile open-source event-logging software for video/audio coding and live observations. Methods Ecol. Evol. 7, 1325-1330 (2016).

72. Speakman, J. R., Gidney, A., Bett, J., Mitchell, I. P. \& Johnson, M. S. Limits to sustained energy intake IV: Effect of variation in food quality on lactating mice Mus musculus. J. Exp. Biol. 204, 1957-1965 (2001).

73. Wilson, R. C., Thomas, V., Lanier, D. L. \& Dewsbury, D. A. Open-field behavior in Muroid rodents. Behav. Biology. 17, 495-506 (1976).

74. Telonis, A. G. \& Margarity, M. Phobos: a novel software for recording rodents' behavior during the thigmotaxis and the elevated plus-maze test. Neurosci. letters. 599, 81-85 (2015).

75. Bradford, M. M. A rapid and sensitive method for the quantitation of microgram quantities of protein utilizing the principle of protein-dye binding. Anal. biochemistry. 72, 248-254 (1976).

76. Moyes, C. D., Mathieu-Costello, O. A., Tsuchiya, N., Filburn, C. \& Hansford, R. G. Mitochondrial biogenesis during cellular differentiation. Am. J. Physiol. Cell Physiol. 272, C1345-C1351 (1997).

77. Sidell, B. D., Driedzic, W. R., Stowe, D. B. \& Johnston, I. A. Biochemical correlations of power development and metabolic fuel preferenda in fish hearts. Physiol. Zool. 60, 221-232 (1987).

78. Koo, T. K. \& Li, M. Y. A guideline of selecting and reporting intraclass correlation coefficients for reliability research. J. Chiropr. Med. 15, 155-163 (2016)

79. Symonds, M. R. \& Moussalli, A. A brief guide to model selection, multimodel inference and model averaging in behavioural ecology using Akaike's information criterion. Behav. Ecol. Sociobiol. 65, 13-21 (2011).

80. Nagy, K. A., Girard, I. A. \& Brown, T. K. Energetics of free-ranging mammals, reptiles, and birds. Annu. Rev. Nutr. 19, 247-277 (1999).

\section{Acknowledgements}

We are grateful to Andrés Sazo and Samuel Peña for technical support. We thank Dr. Francisco Bozinovic for his useful comments on an earlier version of the manuscript. This work was funded by Beca Doctorado Nacional (CONICYT): 21130034 and Postdoctorado FONDECYT: 3180108 to IP-V. ANID PIA/BASAL [grant number FB 0002-2014] to PS.

\section{Author contributions}

I.P.-V., P.S. and V.P. designed research. I.P.-V., I.C.-M. and P.L. performed research. I.P.-V. and I.C.-M. analyzed data. I.P.-V., P.S. and V.P. wrote the paper.

\section{Competing interests}

The authors declare no competing interests.

\section{Additional information}

Correspondence and requests for materials should be addressed to V.P. or P.S.

Reprints and permissions information is available at www.nature.com/reprints.

Publisher's note Springer Nature remains neutral with regard to jurisdictional claims in published maps and institutional affiliations.

(c) (i) Open Access This article is licensed under a Creative Commons Attribution 4.0 International License, which permits use, sharing, adaptation, distribution and reproduction in any medium or format, as long as you give appropriate credit to the original author(s) and the source, provide a link to the Creative Commons license, and indicate if changes were made. The images or other third party material in this article are included in the article's Creative Commons license, unless indicated otherwise in a credit line to the material. If material is not included in the article's Creative Commons license and your intended use is not permitted by statutory regulation or exceeds the permitted use, you will need to obtain permission directly from the copyright holder. To view a copy of this license, visit http://creativecommons.org/licenses/by/4.0/.

(c) The Author(s) 2020 